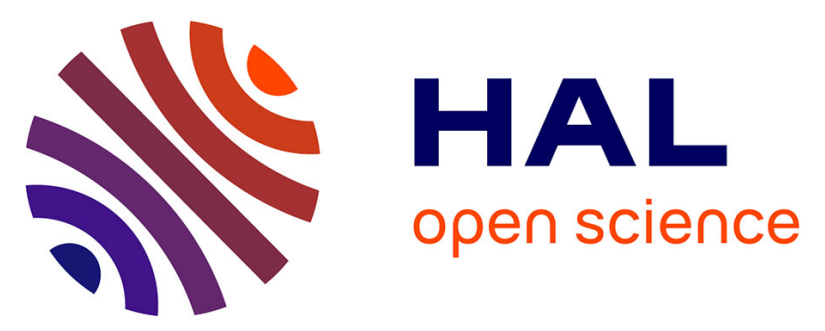

\title{
Patients with diabetes are at high risk of serious medication errors at hospital: Interest of clinical pharmacist intervention to improve healthcare
}

Cyril Breuker, Océane Abraham, Laura Di Trapanie, Thibault Mura, Valérie

Macioce, Catherine Boegner, Anne Jalabert, Maxime Villiet, Audrey

Castet-Nicolas, Antoine Avignon, et al.

\section{To cite this version:}

Cyril Breuker, Océane Abraham, Laura Di Trapanie, Thibault Mura, Valérie Macioce, et al.. Patients with diabetes are at high risk of serious medication errors at hospital: Interest of clinical pharmacist intervention to improve healthcare. European Journal of Internal Medicine, 2017, 38, pp.38 - 45. 10.1016/j.ejim.2016.12.003 . hal-01793426

\section{HAL Id: hal-01793426 \\ https://hal.science/hal-01793426}

Submitted on 13 Dec 2019

HAL is a multi-disciplinary open access archive for the deposit and dissemination of scientific research documents, whether they are published or not. The documents may come from teaching and research institutions in France or abroad, or from public or private research centers.
L'archive ouverte pluridisciplinaire HAL, est destinée au dépôt et à la diffusion de documents scientifiques de niveau recherche, publiés ou non, émanant des établissements d'enseignement et de recherche français ou étrangers, des laboratoires publics ou privés. 


\title{
Patients with diabetes are at high risk of serious medication errors at hospital: Interest of clinical pharmacist intervention to improve healthcare
}

\author{
Cyril Breuker ${ }^{\mathrm{a}, \mathrm{b}, *}$, Océane Abraham ${ }^{\mathrm{a}}$, Laura di Trapanie ${ }^{\mathrm{a}}$, Thibault Mura ${ }^{\mathrm{c}}$, Valérie Macioce ${ }^{\mathrm{c}}$, \\ Catherine Boegner ${ }^{\mathrm{d}}$, Anne Jalabert ${ }^{\mathrm{a}}$, Maxime Villiet ${ }^{\mathrm{a}}$, Audrey Castet-Nicolas ${ }^{\mathrm{a}}$, \\ Antoine Avignon ${ }^{\mathrm{b}, \mathrm{d}}$, Ariane Sultan ${ }^{\mathrm{b}, \mathrm{d}}$ \\ a Clinical Pharmacy Department, University Hospital, 191 Avenue du Doyen Gaston Giraud, 34295 Montpellier, France \\ b PhyMedExp, University of Montpellier, INSERM U1046, CNRS UMR 9214, 371 Avenue du Doyen G. Giraud, 34295 Montpellier, France \\ c Clinical Research and Epidemiology Unit, University Hospital, 39 Avenue Charles Flahault, 34295 Montpellier, France \\ d Endocrinology-Diabetology-Nutrition Department, University Hospital, 191 Avenue du Doyen Gaston Giraud, 34295 Montpellier, France
}

Keywords:

Medication reconciliation

Medication errors

Diabetes mellitus

Pharmaceutical care

Safety

\begin{abstract}
A B S T R A C T
Background: Medication errors (ME) are major public health issues in hospitals because of their consequences on patients' morbi-mortality. This study aims to evaluate the prevalence of ME at admission and discharge of hospitalization in diabetic and non-diabetic patients, and determine their potential clinical impact.

Method: This prospective observational study was conducted at the Endocrinology-Diabetology-Nutrition Department. All adult patients admitted were eligible. A total of 904 patients were included, of which 671 (74.2\%) with diabetes mellitus. Clinical pharmacists conducted medication reconciliation: they collected the Best Possible Medication History and then compared it with admission and discharge prescriptions to identify medication discrepancies. ME were defined as unintended medication discrepancies if corrected by the physician.

Results: Clinical pharmacists allowed correcting ME in 176/904 (19.5\%) patients at admission and in 86/865 (9.9\%) patients at discharge. More than half of ME were omissions. Diabetic patients were more affected by ME than non-diabetic patients, both at admission ( $22.1 \%$ vs $12.0 \%, \mathrm{p}<0.001)$ and at discharge $(11.4 \%$ vs $5.7 \%, \mathrm{p}=$ 0.01 ). The diabetic group also had more potentially severe and very severe ME. Diabetic patients had on average twice more medications than non-diabetic patients $(8.7 \pm 4.5$ vs $4.4 \pm 3.4, \mathrm{p}<0.001)$. The polypharmacy associated with diabetes, but not diabetes mellitus itself, was identified as a risk factor of ME.

Conclusions: The intervention of clinical pharmacists allowed correcting $378 \mathrm{ME}$ in $25.8 \%$ of the cohort before they caused harm. Clinicians, pharmacists and other health care providers should therefore work together to improve patients' safety, in particular in high-risk patients such as diabetic patients.
\end{abstract}

\section{Introduction}

Medication errors (ME) and adverse drug events (ADE) are major public health issues in hospitals because of their consequences on patients' morbi-mortality and economic costs [1]. In 2000, a report of the Institute of Medicine indicated that from 44,000 to 98,000 deaths occur each year secondary to medical errors [2]. The most common type of error is ME, responsible for 7000 deaths per year. ME is defined as "any preventable event that may cause or lead to inappropriate medication use or patient harm while the medication is in the control of the health care professional, patient, or consumer". Such events may be

* Corresponding author at: Clinical Pharmacy Department, University Hospital, 191 Avenue du Doyen Gaston Giraud, 34295, Montpellier, France.

E-mail address: c-breuker@chu-montpellier.fr (C. Breuker). related to professional practice, health care products, procedures, and systems, including prescribing, order communication, product labeling, packaging, nomenclature, compounding and dispensing. ADE is defined as "any undesirable experience associated with the use of a medical product in a patient" [3] and includes harm caused by the drug (adverse drug reactions and overdoses) or due to drug use (including dose reductions and discontinuations of drug therapy). ADE may result from ME.

Patients with chronic diseases and comorbidities are at high risk of ADE and ME [4]. Therefore, diabetic patients with their numerous comorbidities associated with polypharmacy with narrow therapeutic index are at risk of safety issues and could be severely affected by ME [5]. However, studies focusing on diabetic patients mainly evaluated the risk of diabetes therapies, such as insulin or oral hypoglycemic agents, but not the overall patient care [6]. Indeed, in addition to diabetes treatment, diabetic patients have other treatments such as cardiovascular medicines also at risk of medication errors [7]. Efforts should 
therefore focus on such high-risk populations [8-10]. Since 2003, the American Diabetes Association (ADA) has included pharmacists in the list of diabetes care team members [4]. Indeed, the intervention of clinical pharmacists has been associated with improved control of major cardiovascular risk factors in diabetes patients (blood pressure, LDL cholesterol and body mass index) [11]. Further, the clinical pharmacist can also set up a medication reconciliation process, associated with decreased risk of ME. Medication reconciliation is the process that compares a patient's medication order to all medications that the patient has been taking and should take at admission, transfer and discharge of hospitalization. Medication reconciliation can identify and resolve ME and therefore contributes to the safety of medication management during patients' healthcare circuit. Studies of medication reconciliation have mainly been carried out in emergency departments or during hospital admission only [12]. To our knowledge, few studies [13] have focused on medical unit and at the two main points of care transition that are admission and discharge and no study was carried out in an endocrinology unit according to diabetes status.

Consequently, the aim of our study was to evaluate the prevalence of ME according to diabetic status, determine the potential clinical impact of ME and investigate the impact of clinical pharmacists' intervention on medication errors prevalence.

\section{Methods}

\subsection{Context}

We conducted this prospective observational study over a 1.5 -year period from November 2013 to May 2015 in the Endocrinology, Diabetology and Nutrition Department of the University Hospital of Montpellier - France. All patients aged above 18 years old admitted to the department during the study period and hospitalized for at least $24 \mathrm{~h}$ were eligible for inclusion. The population was then divided into two groups according to diabetic status.

\subsection{Intervention}

At admission, pharmaceutics' team, including a senior pharmacist, one resident and two pharmacy students, conducted medication reconciliation process within $24 \mathrm{~h}$ of admission or on the first working day following admission for admissions during week-ends. The medication reconciliation process was conducted according to a validated protocol summarized in Fig. 1 [13]. The first step consists of getting the Best Possible Medication History (BPMH), defined as the most comprehensive list of all medications

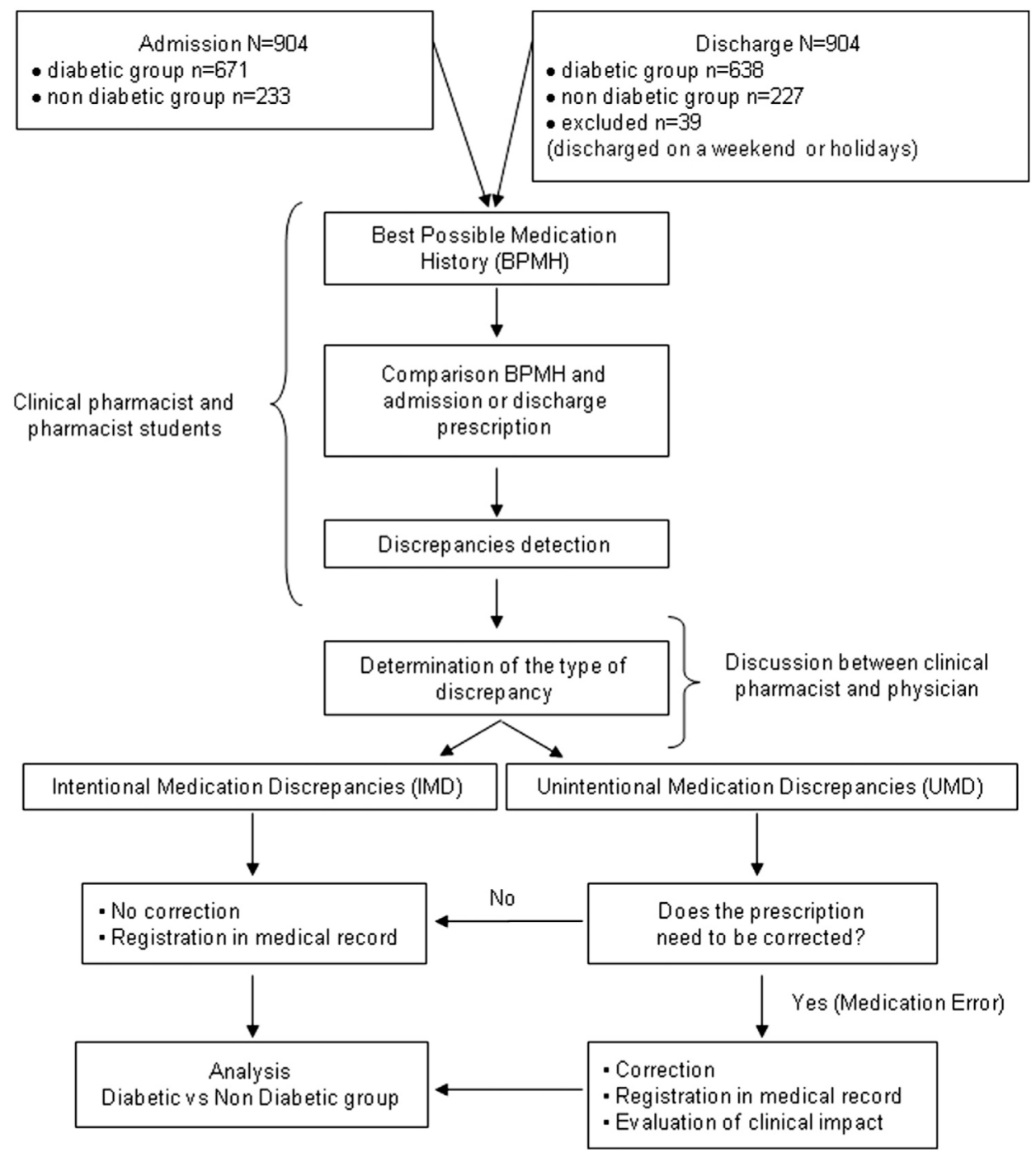

Fig. 1. Principle of medication reconciliation. 
taken by the patient including prescription medication and over the counter medication. Information on drug therapy (name, dosage, dosage forms, frequency of administration) was retrieved through: 1) a detailed and structured patient interview (or family interview if the patient was not able to answer); 2) reading medication orders and listing medication containers brought by the patient; 3 ) phone contact with community pharmacies, physicians and/or nurse; 4) reading previous hospitalizations' reports. The BPMH has to be based on at least 2 sources of information. The second step consists of comparing the BPMH with admission or discharge prescription made by the physician in charge. Any medication difference between BPMH and hospitalization prescription were considered to be a medication discrepancy. A discrepancy could include an omission, an added medication, a modification in dosage or frequency or route of administration. The third step consists of characterizing, solving and documenting discrepancies. Pharmacists and physicians discussed and classified each discrepancy as an intended (IMD) or unintended medication discrepancy (UMD). An IMD was considered to be a voluntary change in the management of patient medication load following hospital care. On the contrary, an UMD was considered to be involuntary and the physician could choose whether or not to make the appropriate changes on his medication prescription. An UMD corrected by the physician was considered to be a ME. The same procedure was followed at the discharge of patients before their departure. At discharge, the BPMH performed from the $\mathrm{BPMH}$ at admission and including all medication modifications made during the hospitalization stay was compared to the discharge prescription form. If the patient was discharged on a weekend, reconciliation was not performed and only the reconciliation at admission was analyzed.

\subsection{Study of the intervention}

Each medication discrepancy and ME highlighted by pharmaceutical team were collected.

ME was classified regarding drug class and errors' types. For each patient with an identified ME, the potential clinical impact was determined through a consensus of an expert panel: 2 pharmacists ( 1 hospital senior pharmacist and the resident) and 2 senior clinicians from the clinical department. Age, presence of chronic diseases and/or comorbidities, body mass index, renal function, number and type of $\mathrm{ME}$ and medication involved were taken in consideration to determine the potential severity of these ME.

The index used to rate the significance of the errors was based on the National Coordinating Council for Medication Error Reporting and Prevention (NCC MERP) Index for categorizing medication errors and adapted to get 4 severity categories with the type of error that leads to this severity: very serious, serious, moderate and minor $[14,15]$ (Table 1 ). The potentially very serious effect was defined for all errors that could lead to very serious or life-threatening consequences for the patient, such as overdose of five times the normal dosage of drug with a narrow therapeutic index. The potentially serious effect was defined for errors that may cause harm or may extend hospital stay duration, such as a route of administration error causing significant toxicity or wrong dose of warfarin. The potentially moderate and minor impacts were defined for errors that affect patients' quality of life and have little consequences for the patient.

\subsection{Measures}

For each patient, demographic, clinical and biological data were collected: age, sex, cause of hospital admission, type of admission (planned or unplanned, via emergency department), period of admissions (weekday or night and week-end) and comorbidities. For each medication, we collected its name, dosage, dosage forms and frequency of administration. For each medication discrepancy, we collected the type of medication discrepancy (omission, added medication, dosage or frequency error or other), the nature of discrepancy (intended or unintended). For each UMD and ME, we collected the drug classes (according to
Table 1

Evaluation of potential clinical impact of medication error.

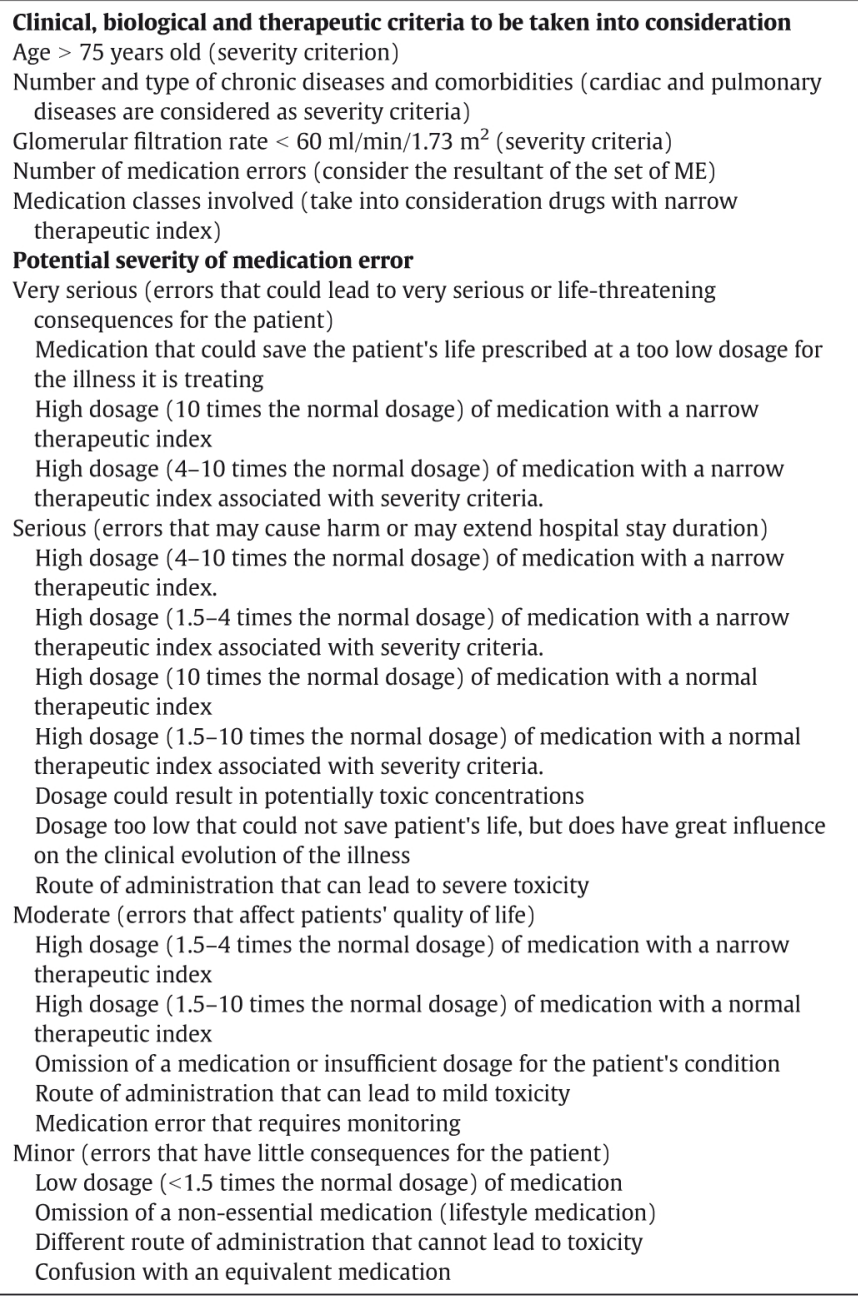

anatomical therapeutic chemical classification system), the correction or not of the UMD and the potential clinical impact of ME for the patient.

\subsection{Analysis}

Patients' characteristics were described with proportions for categorical variables and with means \pm standard deviations (SD) for quantitative variables. These characteristics were compared between diabetic and non-diabetic patients with the Student $t$-test or the Mann-Whiney $U$ test for continuous variables, and with Chi-square or Fisher exact test for categorical variables.

Relation between diabetes and risk of medication errors was analyzed using logistic regression. We first adjusted our model for the period of conciliation in order to take into account the change in medicine and/or pharmacist residents. We then built a model adjusted for the period of conciliation and the number of lines of the prescription at admission or discharge. Because of the non-linearity of the relation between number of lines and risk of medication errors, we modeled risk of medication errors using a spline function of number of lines with a seconddegree polynomial and one central node [16]. We finally added age and sex in a third and final multivariate logistic model.

Statistical analyses were performed at the conventional two-tailed $\alpha$ level of 0.05 using SAS version 9.1 (SAS Institute, Cary, North Carolina). 


\subsection{Ethical considerations}

Our prospective observational study follows the World Medical Association's Declaration of Helsinki. All patients included in our study received normal clinical care. Our interventions consisted of a review of the medication history of patients and a consultation with a clinical pharmacist. In accordance with the French code of public health (article L1121-1) and after notice to the local ethics committee (Sud Méditerranée IV), the local ethics committee has confirmed that our observational study "pharmacist intervention to reduce medication error" does not require any ethic committee approval (notice No. Q-2016-0903). All patients who provided verbal consent were entered into a registry with data collected from their hospitalization including anthropometric, clinical and biological information (No. DC-2009-1052). Only authors involved in the medical management of patients had access to the identification of patients and their medical data. Patient data were then anonymized by removing any identifying information before being analyzed.

\section{Results}

\subsection{Patients' characteristics}

Our whole cohort included 904 patients, with a mean age of $55.9 \pm$ 16.6 years old, a sex ratio close to 1 and 671 patients (74.2\%) suffering from diabetes mellitus, mainly type 2 diabetes (75.7\%). Baseline characteristics of our patients according to diabetic status are presented in

Table 2

Baseline characteristics of study patients, according to diabetic status.

\begin{tabular}{|c|c|c|c|}
\hline & DP & NDP & $\mathrm{p}$ value \\
\hline Number of patients $(n)$ & 671 & 233 & \\
\hline Age, years (mean $\pm S D$ ) & $58.4 \pm 15.8$ & $49.1 \pm 16.9$ & $<0.001$ \\
\hline Sex & & & $<0.001$ \\
\hline Male, $n(\%)$ & $404(60.2 \%)$ & $54(23.2 \%)$ & \\
\hline Female, $n(\%)$ & $267(39.9 \%)$ & $179(76.8 \%)$ & \\
\hline $\mathrm{BMI}>30 \mathrm{~kg} / \mathrm{m}^{2}, n(\%)$ & $314(46.8 \%)$ & $173(74.2 \%)$ & $<0.001$ \\
\hline Type of diabetes & & & $<0.001$ \\
\hline Type $1, n(\%)$ & $163(24.3 \%)$ & - & \\
\hline Type $2, n(\%)$ & $508(75.7 \%)$ & - & \\
\hline \multicolumn{4}{|l|}{ Admission reason } \\
\hline Diabetes discovery, $n$ (\%) & $27(4.0 \%)$ & 0 & $<0.001$ \\
\hline Imbalanced diabetes, $n(\%)$ & $433(64.5 \%)$ & 0 & $<0.001$ \\
\hline Diabetic foot, $n(\%)$ & $160(23.8 \%)$ & 0 & $<0.001$ \\
\hline Treatment of obesity, $n(\%)$ & $27(4.0 \%)$ & $157(67.4 \%)$ & $<0.001$ \\
\hline Adrenocortical dysfunction, $n(\%)$ & $3(0.4 \%)$ & $14(6 \%)$ & $<0.001$ \\
\hline Eating disorders, $n(\%)$ & $1(0.1 \%)$ & $38(16.3 \%)$ & $<0.001$ \\
\hline Thyroid dysfunction, $n$ (\%) & $1(0.1 \%)$ & $8(3.4 \%)$ & $<0.001$ \\
\hline \multicolumn{4}{|l|}{ Associated chronic diseases } \\
\hline Arterial hypertension, $n(\%)$ & $380(56.6 \%)$ & $83(35.6 \%)$ & $<0.001$ \\
\hline Dyslipidemia, $n(\%)$ & $342(50.9 \%)$ & $50(21.5 \%)$ & $<0.001$ \\
\hline Cardiovascular diseases, $n(\%)$ & $290(43.2 \%)$ & $29(12.4 \%)$ & $<0.001$ \\
\hline Lung diseases, $n(\%)$ & $117(17.4 \%)$ & $42(18.0 \%)$ & 0.92 \\
\hline Infectious diseases, $n(\%)$ & $135(20.1 \%)$ & $15(6.4 \%)$ & $<0.001$ \\
\hline Chronic diseases (mean $\pm S D$ ) & $4.4 \pm 1.9$ & $2.7 \pm 1.7$ & $<0.001$ \\
\hline \multicolumn{4}{|l|}{ Comorbidities, $n(\%)$} \\
\hline Renal failure $\left(\mathrm{DFG}<60 \mathrm{ml} / \mathrm{min} / 1.73 \mathrm{~m}^{2}\right.$ ) & $346(51.6 \%)$ & $80(34.3 \%)$ & $<0.001$ \\
\hline Cardiac failure & $38(5.7 \%)$ & $3(1.3 \%)$ & $<0.005$ \\
\hline Liver dysfunction & $21(3.1 \%)$ & $6(2.6 \%)$ & 0.66 \\
\hline Alcohol consumption & $58(8.6 \%)$ & $9(3.8 \%)$ & $<0.05$ \\
\hline Tobacco use & $162(24 \%)$ & $36(15.4 \%)$ & $<0.01$ \\
\hline \multicolumn{4}{|l|}{ Type of admission } \\
\hline Planned hospitalization, $n(\%)$ & $493(73.5 \%)$ & $195(83.7 \%)$ & $<0.005$ \\
\hline Transfer, $n(\%)$ & $88(13.1 \%)$ & $20(8.6 \%)$ & 0.09 \\
\hline From emergency department, $n(\%)$ & $90(13.4 \%)$ & $18(7.7 \%)$ & 0.02 \\
\hline \multicolumn{4}{|l|}{ Time of admission } \\
\hline Weekday, $n(\%)$ & $624(93.0 \%)$ & $225(96.6 \%)$ & 0.07 \\
\hline Night or week-end, $n(\%)$ & $47(7.0 \%)$ & $8(3.4 \%)$ & 0.07 \\
\hline $\mathrm{GFR}, \mathrm{ml} / \mathrm{min} / 1.73 \mathrm{~m}^{2}($ mean $\pm \mathrm{SD})$ & $78.1 \pm 31.9$ & $94.2 \pm 20.3$ & $<0.001$ \\
\hline
\end{tabular}

Data are mean \pm SD or $n$ (\%). DP, diabetic patients; NDP, non-diabetic patients; GFR, glomerular filtration rate.
Table 2. Diabetic patients were mostly men, were significantly older and had more chronic diseases, such as cardiovascular diseases, as compared with non-diabetic patients. Management diagnoses for the diabetic group were mainly imbalanced diabetes or diabetic foot care whereas non-diabetic patients were mainly admitted for treatment of obesity and eating disorders. Patients with diabetes were mainly admitted via the emergency department whereas hospitalization was mainly planned for patients without diabetes. Patients of both groups were mainly admitted on working days.

\subsection{Medication lists, intentional and unintentional medication discrepancies}

Medication lists (home medication, beginning of hospitalization medication, end of hospitalization medication and discharge medication lists) were analyzed for 904 patients at admission and for 865 of them at discharge. Thirty-nine patients $(4.3 \%)$ were excluded at discharge, mainly because the pharmacist could not analyze the prescription before the patient's discharge. Clinical pharmacists identified 3947 (100\%) discrepancies on the whole cohort, of which 2676 (67.8\%) at admission and 1271 (32.2\%) at discharge. Medication discrepancies were intentional in $90.2 \%$ (IMD) of cases and corresponded to change in drug therapy during hospitalization. The remaining 385 medication discrepancies (9.8\%) were classified as unintentional (UMD). Among them, 98.2\% were corrected by the physician and corresponded to ME. Only seven UMD were maintained by physicians. They were for example decrease or omissions of treatment by proton pomp inhibitors in patients with no history of esophagitis or gastroesophageal reflux disease or of hypnotic treatment in patients without sleep disorder.

\subsubsection{Medication lists according to diabetic status}

Obtaining the BPMH required between 15 and 45 min depending on the patient with an average of $30 \mathrm{~min}$. So, $452 \mathrm{~h}$ and $432.5 \mathrm{~h}$ respectively were required to achieve the $\mathrm{BPMH}$ at the admission and discharge of hospitalization. Diabetic patients had significantly more medications than non-diabetic patients both at home, beginning and end of hospitalization and hospitalization discharge $(\mathrm{p}<0.001)$ (Table 3$)$. Diabetic patients had on average twice more medications $(8.7 \pm 4.5$ vs $4.4 \pm 3.4$, $\mathrm{p}<0.001$ ).

Both groups of patients had an increased number of treatments between home and hospitalization discharge, which was significant for the diabetic group only (diabetic patients $8.2 \pm 4.5$ vs $9.0 \pm 4.3$, $\mathrm{p}<0.001$; non-diabetic patients $4.4 \pm 3.5$ vs $4.7 \pm 3.2$, $\mathrm{p}=0.09$ ).

\subsubsection{Intentional medication discrepancies}

Treatment was modified (IMD) in respectively $80 \%$ and $60 \%$ of diabetic patients at admission and at discharge, versus respectively $60 \%$ and $52 \%$ in non-diabetic patients $(p<0.001)$ (Table 3 ). Moreover, the diabetic group had more modifications both at admission ( $3.8 \pm 2.7$ vs $2.5 \pm 1.9, \mathrm{p}<0.001)$ and discharge $(2.5 \pm 1.7$ vs $1.8 \pm 1.1, \mathrm{p}<0.001)$. In addition, modifications of treatments were more common at admission than at discharge for both groups $(\mathrm{p}<0.001)$. Overall, diabetic patients had $4.5 \pm 3.7$ modifications of treatment vs $2.4 \pm 2.3$ for nondiabetic patients $(p<0.001)$, that is nearly half of their lines of treatment.

\subsubsection{Unintentional medication discrepancies and medication errors}

Clinical pharmacists identified 385 UMD in 179 patients (19.8\%) at admission and 87 patients (10.1\%) at discharge. After discussion between the clinical pharmacist and the physician, $98.2 \%$ of UMD were corrected and therefore defined as ME, $322(85.2 \%)$ in the diabetic group and $56(14.8 \%)$ in the non-diabetic group. Diabetic patients were more affected by ME than non-diabetic patients both at admission ( $22.1 \%$ vs $12.0 \%, \mathrm{p}<0.005)$ and at discharge ( $11.4 \%$ vs $5.7 \%, \mathrm{p}=0.01)$ (Table 3). Moreover, we observed twice as many ME and patients 
Medication list, intentional and unintentional medication discrepancy characteristics at admission and discharge, according to diabetic status.

\begin{tabular}{|c|c|c|c|c|c|c|c|c|}
\hline & \multicolumn{3}{|l|}{ Admission } & \multirow[b]{2}{*}{$\mathrm{p}$ value } & \multicolumn{3}{|l|}{ Discharge } & \multirow[b]{2}{*}{$\mathrm{p}$ value } \\
\hline & Total $(n=904)$ & $\mathrm{DP}(n=671)$ & $\operatorname{NDP}(n=233)$ & & Total $(n=865)$ & $\mathrm{DP}(n=638)$ & $\operatorname{NDP}(n=227)$ & \\
\hline \multicolumn{9}{|l|}{ Medication list by patient } \\
\hline Home & $7.2 \pm 4.6$ & $8.2 \pm 4.5$ & $4.4 \pm 3.5$ & $<0.001$ & - & - & - & \\
\hline Beginning of hospitalization & $7.3 \pm 4.3$ & $8.3 \pm 4.2$ & $4.3 \pm 3.4$ & $<0.001$ & - & - & - & \\
\hline End of hospitalization & & - & - & & $8.0 \pm 4.7$ & $9.2 \pm 4.5$ & $4.7 \pm 3.4$ & $<0.001$ \\
\hline Discharge & & - & - & & $7.9 \pm 4.5$ & $9.0 \pm 4.3$ & $4.7 \pm 3.2$ & $<0.001$ \\
\hline Number of medication at hospitalization & $6956(100 \%)$ & $5892(100 \%)$ & $1064(100 \%)$ & & $6786(100 \%)$ & $5717(100 \%)$ & $1069(100 \%)$ & \\
\hline \multicolumn{9}{|l|}{ Discrepancies } \\
\hline Number of discrepancies & $2676(38.5 \%)$ & $2282(38.7 \%)$ & $394(37.0 \%)$ & 0.29 & $1271(18.7 \%)$ & $1046(18.3 \%)$ & $225(21 \%)$ & 0.03 \\
\hline Number of patients & 717 (79.3\%) & $567(84.5 \%)$ & $150(64.4 \%)$ & $<0.001$ & $534(61.7 \%)$ & $409(64.1 \%)$ & $125(55.1 \%)$ & $<0.05$ \\
\hline Number of discrepancies per patient & $3.7 \pm 2.7$ & $4.0 \pm 2.8$ & $2.6 \pm 2.0$ & $<0.001$ & $2.4 \pm 1.7$ & $2.6 \pm 1.8$ & $1.8 \pm 1.1$ & $<0.001$ \\
\hline \multicolumn{9}{|l|}{ IMD } \\
\hline Number of IMD & $2403(34.5 \%)$ & $2052(34.8 \%)$ & $351(32.9 \%)$ & 0.24 & $1159(17.1 \%)$ & $950(16.6 \%)$ & 209 (19.5\%) & 0.21 \\
\hline Number of patients & $677(74.9 \%)$ & $537(80.0 \%)$ & $140(60.1 \%)$ & $<0.001$ & $501(57.9 \%)$ & $383(60.0 \%)$ & $118(51.9 \%)$ & $<0.001$ \\
\hline Number of IMD per patient & $3.6 \pm 2.6$ & $3.8 \pm 2.7$ & $2.5 \pm 1.9$ & $<0.001$ & $2.3 \pm 1.7$ & $2.5 \pm 1.7$ & $1.8 \pm 1.1$ & $<0.001$ \\
\hline \multicolumn{9}{|l|}{ UMD } \\
\hline Number of UMD & $273(3.9 \%)$ & $230(3.9 \%)$ & $43(4.0 \%)$ & 0.92 & $112(1.6 \%)$ & $96(1.7 \%)$ & $16(1.5 \%)$ & 0.92 \\
\hline Number of patients & $179(19.8 \%)$ & $149(22.2 \%)$ & $30(12.9 \%)$ & $<0.005$ & $87(10.1 \%)$ & $74(11.6 \%)$ & $13(5.7 \%)$ & $<0.05$ \\
\hline Number of UMD per patient & $1.5 \pm 0.8$ & $1.5 \pm 0.8$ & $1.4 \pm 0.7$ & 0.56 & $1.3 \pm 0.6$ & $1.3 \pm 0.6$ & $1.2 \pm 0.4$ & 0.98 \\
\hline \multicolumn{9}{|l|}{ ME } \\
\hline Number of ME & $267(3.8 \%)$ & $227(3.9 \%)$ & $40(3.8 \%)$ & 0.88 & $111(1.6 \%)$ & $95(1.7 \%)$ & $16(1.5 \%)$ & 0.69 \\
\hline Number of patients & $176(19.5 \%)$ & $148(22.1 \%)$ & $28(12.0 \%)$ & $<0.001$ & $86(9.9 \%)$ & $73(11.4 \%)$ & $13(5.7 \%)$ & 0.01 \\
\hline Number of ME per patient & $1.5 \pm 0.8$ & $1.5 \pm 0.8$ & $1.4 \pm 0.7$ & 0.56 & $1.3 \pm 0.6$ & $1.3 \pm 0.6$ & $1.2 \pm 0.4$ & 0.98 \\
\hline
\end{tabular}

Data are mean \pm SD or $n$ (\%). DP, diabetic patients; NDP, non-diabetic patients; IMD, intentional medication discrepancy; UMD, unintentional medication discrepancy; ME, medication errors. p value, statistical analysis between DP and NDP population at admission and discharge.

involved at admission than at discharge for the diabetic $(p<0.001)$ and non-diabetic groups $(p<0.05)$. Finally, the mean number of ME per patient was similar between groups and between admission and discharge (overall $1.4 \pm 0.7$ ).

\subsubsection{Classification and types of medication errors}

ME are described in Table 4. At admission, diabetic patients had significantly more ME involving medication of the cardiovascular system (33.9\% vs $12.5 \%, \mathrm{p}=0.01$ ). At discharge, medication class of ME did not differ between groups. Furthermore, the type and frequency of ME were comparable between groups, both at admission and at discharge. ME were in more than half of cases omissions, followed by incorrect dose, incorrect frequency and inappropriate added medications. However, in both groups, types of ME did not differ between admission and discharge except for the diabetic group who had more inappropriate added medications at discharge ( $3.9 \%$ vs $15.8 \%, \mathrm{p}<0.001$ ).

\subsubsection{Potential clinical severity of medication errors}

The diabetic group had more severe ME than the non-diabetic group, both at admission ( $33.8 \%$ vs $7.1 \%, \mathrm{p}<0.005$ ) and discharge $(41.1 \%$ vs $0 \%$, $\mathrm{p}<0.005$ ) (Table 4$)$. They had less minor errors at admission $(25.7 \%$ vs $42.9 \%, \mathrm{p}=0.06$ ) although the difference was not statistically significant and significantly less moderate errors at discharge (35.6\% vs $69.2 \%, \mathrm{p}=$ $0.03)$. Examples of ME considered to have potential to cause severe or very severe clinical impact are described in Table 5.

\subsubsection{Risk factors of medication errors}

Results for the association between diabetes and the risk of ME are shown in Table 6. In model 1 adjusted for the period of admission, diabetic status was significantly associated with the risk of ME both at admission and discharge. However, this association was no longer significant after adjusting for the number of treatments. Conclusions were not modified after adjusting for age and sex (model 3 ). Thus,

Medication error characteristics at admission and discharge, according to diabetic status.

\begin{tabular}{|c|c|c|c|c|c|c|}
\hline & \multicolumn{3}{|l|}{ Admission } & \multicolumn{3}{|l|}{ Discharge } \\
\hline & $\mathrm{DP}(n=671)$ & $\operatorname{NDP}(n=233)$ & $\mathrm{p}$ value & $\mathrm{DP}(n=638)$ & $\operatorname{NDP}(n=227)$ & $\mathrm{p}$ value \\
\hline \multicolumn{7}{|l|}{ Medication involved in ME } \\
\hline ATC code A, $n(\%)$ & $56(24.7 \%)$ & $10(25 \%)$ & 0.87 & $29(30.5 \%)$ & $6(37.5 \%)$ & 0.81 \\
\hline ATC code B, $n(\%)$ & $17(7.5 \%)$ & $0(0 \%)$ & 0.08 & $11(11.6 \%)$ & $0(0 \%)$ & 0.35 \\
\hline ATC code C, $n(\%)$ & $77(33.9 \%)$ & $5(12.5 \%)$ & 0.01 & $18(18.9 \%)$ & $1(6.2 \%)$ & 0.29 \\
\hline ATC code $\mathrm{N}, n(\%)$ & $40(17.6 \%)$ & $10(25 \%)$ & 0.37 & $21(22.1 \%)$ & $5(31.2 \%)$ & 0.52 \\
\hline ATC code $\mathrm{R}, n(\%)$ & $9(3.9 \%)$ & $4(10 \%)$ & 0.08 & $6(6.3 \%)$ & $3(18.7 \%)$ & 0.12 \\
\hline ATC code others, $n(\%)$ & $28(12.3 \%)$ & $11(27.5 \%)$ & 0.02 & $10(10.5 \%)$ & $1(6.2 \%)$ & 1 \\
\hline \multicolumn{7}{|l|}{ Type of ME ( $n, \%)$} \\
\hline Added medication, $n(\%)$ & $9(3.9 \%)$ & $1(2.5 \%)$ & 1 & $15(15.8 \%)$ & $1(6.2 \%)$ & 0.46 \\
\hline Omission, $n(\%)$ & $132(58.1 \%)$ & $21(52.5 \%)$ & 0.62 & $60(63.2 \%)$ & $11(68.7 \%)$ & 0.86 \\
\hline Wrong dose, $n(\%)$ & $65(28.6 \%)$ & $12(30.0 \%)$ & 0.99 & $17(17.9 \%)$ & $2(12.5 \%)$ & 0.73 \\
\hline Wrong frequency, $n(\%)$ & $21(9.2 \%)$ & $6(15.0 \%)$ & 0.26 & $3(3.2 \%)$ & $2(12.5 \%)$ & 0.15 \\
\hline \multicolumn{7}{|c|}{ Potential clinical gravity of ME by patient } \\
\hline Minor, $n(\%)$ & $38(25.7 \%)$ & $12(42.9 \%)$ & 0.06 & $17(23.3 \%)$ & $4(30.8 \%)$ & 0.73 \\
\hline Moderate, $n(\%)$ & $58(39.2 \%)$ & $14(50 \%)$ & 0.28 & $26(35.6 \%)$ & $9(69.2 \%)$ & 0.03 \\
\hline Severe, $n(\%)$ & $50(33.8 \%)$ & $2(7.1 \%)$ & $<0.005$ & $30(41.1 \%)$ & $0(0 \%)$ & $<0.005$ \\
\hline Very severe, $n(\%)$ & $2(1.3 \%)$ & $0(0 \%)$ & 1 & $0(0 \%)$ & $0(0 \%)$ & \\
\hline
\end{tabular}

Data are mean \pm SD or $n$ (\%). DP, diabetic patients; NDP, non-diabetic patients; ME, medication errors; ATC, anatomical therapeutic classification; A, alimentary tract and metabolism; B, blood and blood forming organ; C, cardiovascular system; N, nervous system; R, respiratory system. 
Table 5

Examples of medication errors considered to have potential to cause severe or very severe clinical impact

\section{Type of medication Description}

error

\section{Omission}

Wrong dose or dosage

Unjustified added medication

Others

- Omission of antiretroviral therapy in patient with HIV disease

- Omission of diuretic treatment in patient with renal failure, arterial hypertension and edema of the lower limbs

- Omission of antihypertensive and antiplatelet treatment in patient with arterial hypertension and coronary syndrome

- Omission of double antihypertensive therapy, antiplatelet and cholesterol lowering treatment in patient with arterial hypertension, coronary artery disease and dyslipidemia

- Omission of double antibiotic therapy in patient with diabetic foot infection

- Twofold decrease in the immunosuppressive treatment dose in patient with sarcoidosis multi organ disease with pulmonary involvement and pulmonary arterial hypertension

- Fivefold decrease in the dose of replacement therapy for opioid drug dependence in patient with terminal renal failure and psychiatric disorder

- Threefold increase in the dose of hypnotic treatment in patient with depressive syndrome, psychiatric disease and with medical history of addiction disease.

- Doubling of the dose of anticoagulant treatment in patient with renal failure

- Fourfold increase in the dose of antiepileptic treatment in patient with terminal renal failure

- Threefold increase in the dose of hypoglycemic sulfamide at hospitalization discharge in patient with imbalanced diabetes and renal failure

- Prescription of insulin glargine instead of insulin detemir at the same dose in patient with imbalanced diabetes

- Prescription on discharge medical order of human albumin and nicorandil treatment when they were stopped during hospitalization in patient with cardiac disease and terminal renal failure

- Decrease in the dose of antibiotic treatment for osteitis infection and omission of prophylactic anticoagulant treatment in patient with diabetic foot disease.

- Decrease in the dose of curative anticoagulant therapy and omission of antihypertensive treatment in patient with diabetic foot disease and deep vein thrombosis.

these results underscored the relationship between polypharmacy and the risk of ME in the diabetic population.

\section{Discussion}

In our study, we evaluated for the first time the incidence and type of ME according to diabetes status, their potential clinical impact and the effect of adding pharmacist to care team on the detection and correction of these ME. Our results showed that diabetic patients are exposed to more ME both at admission and at discharge, with more potentially serious ME. Furthermore, we highlighted that the presence of clinical pharmacist in care unit allowed detecting and correcting ME in 25.8\% of our cohort.

We showed that diabetic patients had twice more treatments than non-diabetic patients, both at admission and at discharge, and more modifications of their treatments during hospitalization. It is well known that the number of prescribed drugs is high or excessive in people with diabetes mellitus [17]. The study of S. Bauer and M.A. Nauck showed on the one hand that diabetic patients had many chronic diseases and comorbidities and on the other hand that patients with type 2 diabetes had an average of 8 medications prescribed and justified by the guidelines [18]. This may cause drug-drug interactions, ADE, ME and compliance issues [19-22].

Clinical pharmacists highlighted UMD in 179 patients (19.8\%) at admission and 87 patients $(10.1 \%$ ) at discharge i.e. $26.0 \%$ of the total population; $98.2 \%$ of them were corrected after discussion with the physician, and therefore defined as ME. This high corrective rate demonstrates the relevance of pharmacist interventions and the trust relationship between the pharmacist and the physician in the medical team. Thus, in the whole cohort, clinical pharmacists allowed correcting these $378 \mathrm{ME}$ before they resulted in harm. These ME concerned mainly diabetic patients both at admission and at discharge. Indeed, $22.1 \%$ of diabetic patients and $12.0 \%$ of non-diabetic patients had at least one ME at admission, and they were respectively $11.4 \%$ and $5.7 \%$ at discharge. Our study is original for at least two raisons: firstly because it compared the incidence and severity of ME between two groups, at admission and discharge of hospital and secondly because it was carried out in a medicine department. Indeed, most studies have focused on emergency department, only at the admission and in the general population [12]. Few studies reported the percentage of patients with at least one UMD or ME at admission and discharge [13,23-26]. These studies reported percentages of patients with ME ranging from $8.3 \%$ to $64.5 \%$ at admission and from 32 to $65 \%$ at discharge. These differences are probably explained by the population characteristics (age, emergency or medicine department), the methodology and definition of ME [27]. Moreover, some studies reported on discrepancies but did not specify if they were intentional, unintentional or ME. In addition, the variation of the incidence of ME between admission and discharge of hospitalization also varied across studies. Some studies found more errors at admission than at discharge ( $64.5 \%$ vs $32.37 \%$ ) whereas others found the contrary ( $8.3 \%$ vs $65.2 \%$ ) or comparable rates between admission and discharge (28\% vs $25 \%$; $42 \%$ vs $39 \%$ and $38 \%$ vs $41 \%$ ) [ $13,23-26]$. In our study, patients had mainly planned hospitalizations and only few patients were hospitalized via the emergency department, on night or on weekends, contrary to some works. Thus errors may be due to a lack of information rather than to a lack of time or to the urgency of the prescription. As described in the literature, the most common ME was the omission of medication. Further, the major medications involved in ME were medication of the alimentary tract and metabolism including antidiabetic drugs, followed by cardiovascular system drugs known to have serious side effects [28,29].

The statistical analysis showed that the polypharmacy associated with diabetes, but not diabetes mellitus itself, was a risk factor of ME. The profile of diabetic patients with a significant number of chronic pathologies, comorbidities and therefore treatments explain this higher

Table 6

Relation between diabetic status and the risk of medication errors: multiple logistic regression analysis.

\begin{tabular}{|c|c|c|c|c|c|c|}
\hline \multirow[t]{2}{*}{ Adjusted odds ratio $(95 \% \mathrm{CI})$} & \multicolumn{3}{|l|}{ Admission } & \multicolumn{3}{|l|}{ Discharge } \\
\hline & DP & NDP & $\mathrm{p}$ value & DP & NDP & $\mathrm{p}$ value \\
\hline Statistical model 1 & $1.79(1.15-2.80)$ & 1 & 0.01 & $1.96(1.06-3.63)$ & 1 & 0.03 \\
\hline Statistical model 2 & $1.08(0.66-1.76)$ & 1 & 0.76 & $0.70(0.35-1.42)$ & 1 & 0.32 \\
\hline Statistical model 3 & $1.16(0.69-1.93)$ & 1 & 0.57 & $0.65(0.31-1.37)$ & 1 & 0.26 \\
\hline
\end{tabular}

Data are mean \pm SD or $n(\%)$. DP, diabetic patients; NDP, non-diabetic patients; CI, confidence limits. Statistical model 1, model adjusted for the period of admission; statistical model 2 model adjusted for the period of admission and the number of lines of the prescription at admission or discharge; statistical model 3, model adjusted for the period of admission, the number of lines of the prescription at admission or discharge, age and sex of the patient. 
risk of ME. Thus, the largest number of ME in the diabetic population could be explained by a greater number of lines of treatment both at admission and at discharge but also by the fact that their treatments are much more modified during hospitalization. Indeed, several studies have shown that age, average number of medication or number of medication change to discharge were risk factors of $\operatorname{ME}[30,31]$.

The diabetic group had not only more ME but also a higher proportion of potentially severe and very severe ME (damage to a vital organ or extended length of hospital stay) at admission (33.8\%) and discharge (41.1\%) with an increase in severe ME at discharge. The methodologies used to assess the potential clinical impact of ME varied between studies, making comparisons difficult. However, we observed a higher proportion of potentially serious ME in the diabetic population than in other similar studies. Thereby, many authors showed lower proportions of ME with potential harm at admission on medicine department (6.4\%, $10.4 \%, 3.5 \%$ and $2.7 \%$ respectively); which are comparable with the rates found in our non-diabetic population (7.1\%) [13,23,29,31]. Regarding discharge, fewer studies have investigated the potential impact of ME. They reported proportions of potentially severe ME ranging from 3.4\% to $25 \%$, which are lower than that found in our diabetic population $[13,23]$. Our proportion of potentially severe ME may be due to the fragility of our diabetic patients with several chronic diseases and narrow therapeutic index treatments.

According to the literature, 10 to $67 \%$ of medication histories contain at least one error [32]. Medication history errors may result in adverse drug events, interrupted or inappropriate drug therapy during and following hospital stay. Thus, accurate medication histories are a major element of medication safety. The lack of communication between health professionals at points of care transition may often lead to discrepancies and $\mathrm{ME}$ between medications taken by the patient and medical prescription [33]. Some studies have reported that pharmacists but also student pharmacists were one of the best health care providers to make medication history, [34-37] reduced prescribing costs and decreased the potential risk of severe ME $[38,39]$. Indeed, pharmacists have access to all patient information, can interview the patient and his pharmacy and work directly with physicians and nurses. Moreover, pharmacists are trained to optimize drug therapy, particularly when the drug therapy is complex and to improve safe medication use. A multidisciplinary team is an important element to manage patients with diabetes mellitus, which is a complex disease. The clinical pharmacist can be a complementary member of this multidisciplinary team.

\subsection{Limitations}

To our knowledge, this is the first study comparing the incidence and severity of ME between diabetic and non-diabetic patients, both at admission and discharge. In addition, our diabetic population was representative of a hospital population with chronic diseases and diabetes complications, such as renal impairment and diabetic foot ulcer, leading to a large number of treatments. This was due to an exhaustive recruitment and by broad inclusion criteria, as all patients over eighteen years were included. However, our study has some limitations, mainly due to its observational design without any control arm.

\section{Conclusions}

ME are frequent, both at admission and at discharge of hospitalization, in particular in patients with a significant number of treatments such as diabetes patients. Improving the quality and safety of drug therapy is an objective of all health systems. Thus, detection, reporting, analysis and correction of ME are vital to ensure patient safety in particular at points of transition care. Clinicians, pharmacists and other healthcare workers should therefore work together to reduce such ME, in particular in high-risk patients such as diabetic patients.

\section{Funding}

This research did not receive any specific grant from funding agencies in the public, commercial, or not-for-profit sectors.

\section{Competing interests}

None declared.

\section{References}

[1] Khan LM. Comparative epidemiology of hospital-acquired adverse drug reactions in adults and children and their impact on cost and hospital stay-a systematic review. Eur J Clin Pharmacol 2013;69:1985-96.

[2] Brennan TA. The Institute of Medicine report on medical errors-could it do harm? N Engl J Med 2000;342:1123-5.

[3] Duthie E, Favreau B, Ruperto A, Mannion J, Flink E, et al. Quantitative and qualitative analysis of medication errors: the New York experience. In: Henriksen K, Battles JB, Marks ES, Lewin DI, editors. Advances in patient safety: from research to implementation (volume 1: research findings); 2005 Rockville (MD).

[4] Bell CM, Brener SS, Gunraj N, Huo C, Bierman AS, et al. Association of ICU or hospita admission with unintentional discontinuation of medications for chronic diseases. JAMA 2011;306:840-7.

[5] Standards of medical care in diabetes-2015 abridged for primary care providersClin Diab 2015;33:97-111.

[6] Milligan FJ, Krentz AJ, Sinclair AJ. Diabetes medication patient safety incident reports to the National Reporting and Learning Service: the care home setting. Diabet Med 2011;28:1537-40.

[7] Freedman JE, Becker RC, Adams JE, Borzak S, Jesse RL, et al. Medication errors in acute cardiac care: an American Heart Association scientific statement from the Council on Clinical Cardiology Subcommittee on Acute Cardiac Care, Council on Cardiopulmonary and Critical Care, Council on Cardiovascular Nursing, and Council on Stroke. Circulation 2002;106:2623-9.

[8] Chen L, Magliano DJ, Zimmet PZ. The worldwide epidemiology of type 2 diabetes mellitus-present and future perspectives. Nat Rev Endocrinol 2012;8:228-36.

[9] Bates D, Clark NG, Cook RI, Garber JR, Hellman R, et al. American College of Endocrinology and American Association of Clinical Endocrinologists position statement on patient safety and medical system errors in diabetes and endocrinology. Endocr Pract 2005;11:197-202.

[10] Crowe DJ. The American Diabetes Association should be a leader in reducing medication errors. Diabetes Care 2001:24:1841.

[11] Santschi V, Chiolero A, Paradis G, Colosimo AL, Burnand B. Pharmacist interventions to improve cardiovascular disease risk factors in diabetes: a systematic review and meta-analysis of randomized controlled trials. Diabetes Care 2012;35:2706-17.

[12] Mekonnen AB, McLachlan AJ, Brien JE. Pharmacy-led medication reconciliation programmes at hospital transitions: a systematic review and meta-analysis. J Clin Pharm Ther 2016.

[13] Belda-Rustarazo S, Cantero-Hinojosa J, Salmeron-Garcia A, Gonzalez-Garcia L Cabeza-Barrera J, et al. Medication reconciliation at admission and discharge: an analysis of prevalence and associated risk factors. Int J Clin Pract 2015;69:1268-74.

[14] Hartwig SC, Denger SD, Schneider PJ. Severity-indexed, incident report-based medication error-reporting program. Am J Hosp Pharm 1991;48:2611-6.

[15] Fernandez-Llamazares CM, Pozas M, Feal B, Cabanas MJ, Villaronga M, et al. Profile of prescribing errors detected by clinical pharmacists in paediatric hospitals in Spain. Int J Clin Pharm 2013;35:638-46.

[16] Harrell F. Regression modeling strategies: with applications to linear models, logistic regression, and survival analysis. Statistics SSi; 2001 (editor).

[17] Diez-Manglano J, Gimenez-Lopez M, Garces-Horna V, Sevil-Puras M, Castellar-Otin E, et al. Excessive polypharmacy and survival in polypathological patients. Eur J Clin Pharmacol 2015;71:733-9.

[18] Bauer S, Nauck MA. Polypharmacy in people with type 1 and type 2 diabetes is justified by current guidelines-a comprehensive assessment of drug prescriptions in patients needing inpatient treatment for diabetes-associated problems. Diabet Med 2014;31:1078-85.

[19] Huang ES, Karter AJ, Danielson KK, Warton EM, Ahmed AT. The association between the number of prescription medications and incident falls in a multi-ethnic population of adult type-2 diabetes patients: the diabetes and aging study. J Gen Intern Med 2010;25:141-6.

[20] Ho PM, Rumsfeld JS, Masoudi FA, McClure DL, Plomondon ME, et al. Effect of medication nonadherence on hospitalization and mortality among patients with diabetes mellitus. Arch Intern Med 2006;166:1836-41.

[21] Capoccia K, Odegard PS, Letassy N. Medication adherence with diabetes medication: a systematic review of the literature. Diabetes Educ 2016;42:34-71.

[22] Grant RW, Devita NG, Singer DE, Meigs JB. Polypharmacy and medication adherence in patients with type 2 diabetes. Diabetes Care 2003;26:1408-12.

[23] Feldman LS, Costa LL, Feroli Jr ER, Nelson T, Poe SS, et al. Nurse-pharmacist collaboration on medication reconciliation prevents potential harm. J Hosp Med 2012;7: 396-401.

[24] Salanitro AH, Osborn CY, Schnipper JL, Roumie CL, Labonville S, et al. Effect of patient- and medication-related factors on inpatient medication reconciliation errors. J Gen Intern Med 2012;27:924-32.

[25] Vira T, Colquhoun M, Etchells E. Reconcilable differences: correcting medication errors at hospital admission and discharge. Qual Saf Health Care 2006;15:122-6. 
[26] Knez L, Suskovic S, Rezonja R, Laaksonen R, Mrhar A. The need for medication reconciliation: a cross-sectional observational study in adult patients. Respir Med 2011; 105(Suppl. 1):S60-6.

[27] Lehnbom EC, Stewart MJ, Manias E, Westbrook JI. Impact of medication reconciliation and review on clinical outcomes. Ann Pharmacother 2014;48:1298-312.

[28] Magalhaes GF, Santos GN, Rosa MB, Noblat Lde A. Medication reconciliation in patients hospitalized in a cardiology unit. PLoS One 2014;9, e115491.

[29] Quelennec B, Beretz L, Paya D, Blickle JF, Gourieux B, et al. Potential clinical impact of medication discrepancies at hospital admission. Eur J Intern Med 2013:24:530-5.

[30] Pippins JR, Gandhi TK, Hamann C, Ndumele CD, Labonville SA, et al. Classifying and predicting errors of inpatient medication reconciliation. J Gen Intern Med 2008;23: 1414-22.

[31] Gleason KM, McDaniel MR, Feinglass J, Baker DW, Lindquist L, et al. Results of the medications at transitions and clinical handoffs (MATCH) study: an analysis of medication reconciliation errors and risk factors at hospital admission. J Gen Intern Med 2010;25:441-7.

32] Tam VC, Knowles SR, Cornish PL, Fine N, Marchesano R, et al. Frequency, type anc clinical importance of medication history errors at admission to hospital: a systematic review. CMAJ 2005;173:510-5.

33] Boockvar KS, Liu S, Goldstein N, Nebeker J, Siu A, et al. Prescribing discrepancies likely to cause adverse drug events after patient transfer. Qual Saf Health Care 2009;18: 32-6.
[34] Mergenhagen KA, Blum SS, Kugler A, Livote EE, Nebeker JR, et al. Pharmacist- versus physician-initiated admission medication reconciliation: impact on adverse drug events. Am J Geriatr Pharmacother 2012;10:242-50.

[35] Mathys M, Neyland-Turner E, Hamouie K, Kim E. Effect of pharmacy students as primary pharmacy members on inpatient interdisciplinary mental health teams. Am J Health Syst Pharm 2015;72:663-7.

[36] Lancaster JW, Grgurich PE. Impact of students pharmacists on the medication reconciliation process in high-risk hospitalized general medicine patients. Am J Pharm Educ 2014;78:34.

[37] De Winter S, Spriet I, Indevuyst C, Vanbrabant P, Desruelles D, et al. Pharmacist- versus physician-acquired medication history: a prospective study at the emergency department. Qual Saf Health Care 2010;19:371-5.

[38] Fertleman M, Barnett N, Patel T. Improving medication management for patients: the effect of a pharmacist on post-admission ward rounds. Qual Saf Health Care 2005; 14:207-11

[39] Grimes TC, Deasy E, Allen A, O'Byrne J, Delaney T, et al. Collaborative pharmaceutical care in an Irish hospital: uncontrolled before-after study. BMJ Qual Saf 2014;23: 574-83. 